\title{
Research on Practical Teaching of Anatomy for Undergraduate Nursing Program under Information Technology Background in China
}

\author{
Yunfeng Wang', Wei Chen², Luqing Zhang ${ }^{3}$, Lei $\mathrm{Li}^{3}$, Lin $\mathrm{Li}^{3}$, Zijian Ren ${ }^{3}$, Kun Huang4 \\ ${ }^{1}$ Library, Nanjing Medical University, Nanjing, China \\ ${ }^{2}$ Information and Network Center, Nanjing Medical University, Nanjing, China \\ ${ }^{3}$ Department of Human Anatomy, Nanjing Medical University, Nanjing, China \\ ${ }^{4}$ Department of Nursing, Kangda College, Nanjing Medical University, Lianyungang, China \\ Email: ${ }^{\star}$ luqingzh@njmu.edu.cn
}

How to cite this paper: Wang, Y. F., Chen, W., Zhang, L. Q., Li, L., Li, L., Ren, Z. J., \& Huang, K. (2019). Research on Practical Teaching of Anatomy for Undergraduate Nursing Program under Information Technology Background in China. Creative Education, 10, 690-699.

https://doi.org/10.4236/ce.2019.104051

Received: February 8, 2019

Accepted: April 14, 2019

Published: April 17, 2019

Copyright $\odot 2019$ by author(s) and Scientific Research Publishing Inc. This work is licensed under the Creative Commons Attribution International License (CC BY 4.0).

http://creativecommons.org/licenses/by/4.0/

\begin{abstract}
Human anatomy is an important part of the foundation curriculum for undergraduate nursing program in China. Practical teaching of human anatomy plays a key role in consolidating the theoretical knowledge and cultivating students' innovative spirit and practical abilities. With the development of information technology, the characteristics of the nursing specialties combined with information-based education need to be targeted in practical teaching of nursing anatomy. This paper describes a mode we have created for practical teaching, which combines the application of anatomical knowledge and clinical nursing skills in practical teaching; the improvements we have made to the nursing anatomy course are less rote learning, more independent learning, the provision of the online facilities for self-directed learning, the improvement in the quality of the practical laboratory facilities and the humanistic quality of the students' education. These innovations will improve the quality and effectiveness of the nursing anatomy teaching, and promote the provision of high-quality practical personnel training for undergraduate nurses under information technology in China.
\end{abstract}

\section{Keywords}

Human Anatomy, Undergraduate Nursing, Self-Directed Learning, Information Technology

\section{Introduction}

Human anatomy is a core part of the curriculum for the undergraduate nursing 
program in China. Practical teaching is an important component of the teaching of human anatomy, and cannot be replaced by technology or other teaching methods (Biasutto, Caussa, \& del Río, 2006; Saltarelli, Roseth, \& Saltarelli, 2014). Nursing is a traditional profession where nurses provide practical aids to people. Quality, trustworthiness and rigor are the foundations of all care operations. Human anatomical knowledge is required to carry out many nursing techniques including injections, puncture (including endovascular puncture, thoracentesis, pericardial cavity puncture and so on), intubation and first aid. Therefore, anatomy teaching in nursing should have a practical focus (Aversi-Ferreira et al., 2009).

For a long time, the focus of anatomy teaching in nursing has been on systematic anatomy in Chinese medical education (Xiong, Yang, Ji, \& Zhang, 2008). The teaching content emphasized the study of human organs, their position, shape and structure, and the practical class of anatomy in the lab was subordinate to the anatomical lecture. The teaching objectives for practical anatomy are to verify knowledge gleaned from books, and to observe human specimens; however, few courses consider the development and training of anatomical knowledge and the ability to apply it in clinical situations.

With the rapid development of information technology and digital information, students' information behavior has changed. At the same time, the integration of Internet technology and interactive learning have greatly changed the existing nursing teaching model.

To improve the pertinence of practical teaching, to guide students to understand how to learn and to apply their knowledge in practice, the teaching of nursing anatomy in Nanjing Medical University is oriented to train students in professional competence in nursing. Therefore, the college has reformed the teaching content and modes of learning and established practical self-teaching modes, "self-directed learning", focused on developing students' abilities to discover problems, analyze problems and develop problem-solving skills. Additionally, our teaching continuously explores and deepens reform of practical teaching, practical teaching methods, surface anatomy practice and quality training in medical humanities to lay a solid foundation for students in the basic theory and skills, enabling students to take up follow-up courses and carry out clinical nursing work.

\section{Innovating the Practical Teaching Content}

"Valuing systematic observation however neglecting local operation" is a shortcoming that is often present in the practical teaching of anatomy in traditional nursing in China. The training of the nursing students cannot be impressive if without in combination with clinical nursing technology. Therefore, in consideration of the clinical applicability of anatomy, our school participated in compiling "Human Anatomy" (The People's Medical Publishing House, China) for the nursing profession. We have also established a dedicated teaching team. The 
team wrote the handbook "Practical Guidance for Nursing Anatomy", which includes 300 well-designed discussion questions for self-directed learning and is aimed at clinical care applications, in compliance with the nursing anatomy syllabus requirements. Based on systematic anatomy, applied anatomy and surface anatomy for nursing has been integrated in this handbook. The handbook gives detailed internship content and specimen identification method for each chapter.

\section{Improving Practical Teaching Conditions}

To achieve self-directed learning for the students, we not only needed to optimize the teaching content, but also needed to apply modern teaching methods and develop high-quality teaching resources. To break away from conventional teaching methods that are planned, rigid and oriented to curricular activities, we set up a comprehensive, multilevel, open independent learning platform for students.

\section{Equipping Dissection Laboratories with Air Purification System}

In dissection laboratories in Chinese medical colleges air pollution, due to the use of formaldehyde, is a common problem. High formaldehyde concentrations in laboratory air can seriously affect the effectiveness of practical teaching, and harms the health of teachers and students. We have used an advanced negative oxygen ion air purification system (LK Luftqualität AG, In-duct module IMG-F-12, ionair ${ }^{\oplus}$, Switzerland) combined with good ventilation and air-conditioning equipment to transform the anatomy laboratory. The laboratory air quality has now reached levels that comply with the national standard (the irritant limit of formaldehyde is $0.6 \mathrm{mg} / \mathrm{m}^{3}$, national occupational limit 0.5 $\mathrm{mg} / \mathrm{m}^{3}$; refer to the occupational exposure limits for hazardous workplaces in the national occupational health standards (GBZ 2-2002), People's Republic of China), creating an excellent teaching environment for experimental work.

\section{Construction of the Open Laboratory}

High-quality anatomical specimens and pictures of specimens are important resources for independent learning. We have successively built a topographic anatomy lab, a systematic anatomy lab showroom for sectional specimens, a top-quality specimens showroom, and an anatomical simulation laboratory with a total area of $1050 \mathrm{~m}^{2}\left(11,302 \mathrm{ft}^{2}\right)$. There are a total of five open systematic anatomy laboratories, where approximately 2000 newly developed specimens are displayed, each equipped with photos and notes (Figure 1). To facilitate independent learning, students are allowed access to the above laboratories at any time. There are two anatomy simulation laboratories with 80 seats (Figure 2). The computers equip with online learning resources including a multimedia courseware library, a picture library of digital specimens, instructional videos, an 


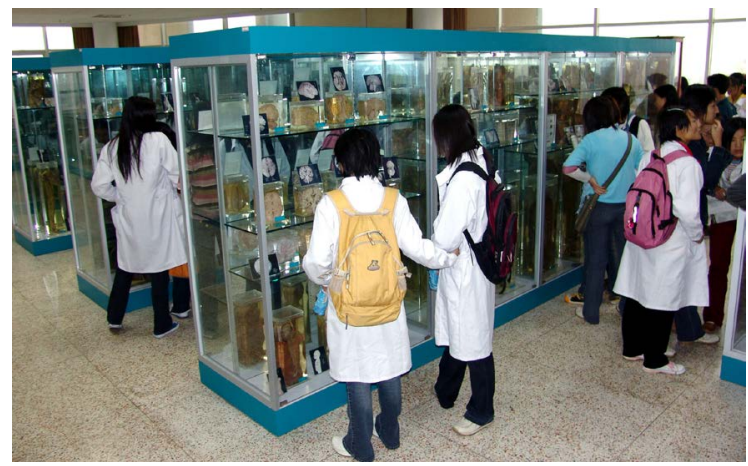

Figure 1. Undergraduate nursing students visit specimens in the human anatomy laboratory.

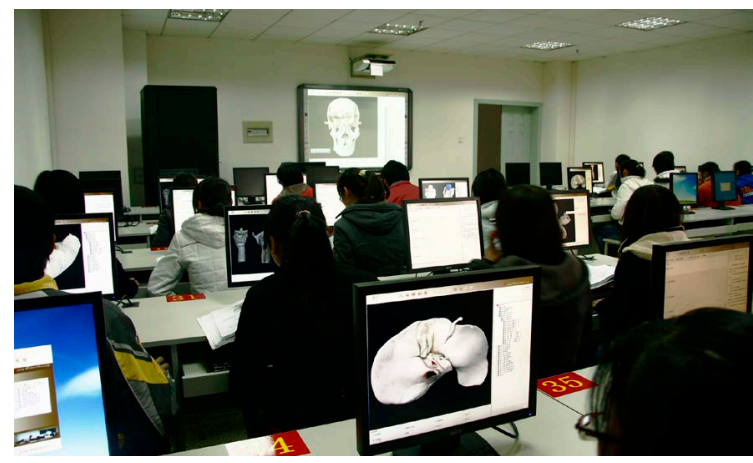

Figure 2. An anatomy simulation laboratory with 80 seats. In this laboratory, the learning software- "learning and exam system for network independent study of human anatomy" is furnished, and online learning resources, including the multimedia courseware library, instructional videos, a questions bank, the syllabus, teaching plans and reference books, are available.

examination database, the syllabus, lesson plans and reference books. We also developed a learning software named "learning and exam system for network independent study of human anatomy" to help self-learning of anatomy, creating a good platform for independent learning.

\section{Innovating Practical Teaching Methods}

\subsection{Encouraging Self-Directed Learning Practice}

An important part of the teaching of practical human anatomy is training students to carry out research studies and develop their spirits of scientific exploration. The traditional practical anatomy teaching used the rote-learning techniques, which lead to students showing less initiative when learning. The "group responsibility system with a leader" has been implemented for practical classes in the nursing anatomy laboratory. Each class is divided into six groups consisting of 5 - 6 students. One student takes their turn to work as the executive leader in each class and organizes their team to observe and discuss specimens, in accordance with the practice content and identification method in the "practice 
guidance" written by the school. The teacher is not allowed to provide demonstration teaching, but is responsible for answering questions and evaluating performances. Through breaking away from the traditional practical teaching methods, in which students observe specimens after the teacher has discussed them, this new practical teaching mode not only develops the students' observation and exploration abilities, but also enables students to obtain excellent self-directed learning and study habits, including collective learning, discussion and exchange, solidarity and cooperation.

Secondly, to improve the level of learning initiative in the students, a teacher may adopt "problem-based" teaching (Becker, Viljoen, Botma, \& Bester, 2003) and appropriately add nursing operations that are related to anatomical knowledge in the laboratory (Table 1). Some examples of this are: precautions for intravenous infusion puncturing are introduced in the practical classes involving the cardiovascular system; after intravenous infusion, the path by which a drug reaches the patient's lesion site; in the practical class of the pleura, the anatomical basis and operation points of the pleural puncture are introduced; during the practical class of the urinary system, the operating points of male and female catheterizations are introduced according to the characteristics of the male and female urethra; in practical class of the artery, the shape characteristics of the brachial artery and the precautions used for blood pressure measurements are emphasized; in the practical class of the tunica of the brain and spinal cord, consideration of the spinal ligaments, anatomical basis and operating points of the lumbar puncture sites and levels are introduced. After class, students analyze, deliberate on the above questions, and access the relevant information. During the practical classes, through simulating the process of venipuncture operation and carefully observing specimens of the cardiovascular system, the students are organized to discuss and answer questions, and finally the teacher will comment on the discussion results and summarize the lesson.

\subsection{Introduction of a Living Anatomy Class}

The contents of practical classes usually are arranged according to the systematic mode of teaching; however, the anatomical knowledge required for practical nursing, such as the essential landmarks for nursing puncture, the essential vascular distribution and the peripheral areas for vascular puncture, is not reflected in the teaching of systematic anatomy. Therefore, we have introduced a living anatomy class (Table 1). We carefully selected approximately 60 human surface structures, compiled and designed a touching method, and provided water-soluble marker pens, stethoscopes, blood pressure meters, tourniquets, and other experimental equipment, for observing, touching and recognizing landmark structures on living bodies. The teacher directs students to touch parts of their own bodies and observe the blood vessels, nerves, bony and muscular landmarks which can be seen and touched to ensure that students fully grasp knowledge of these parts of the anatomy. 
Table 1. Teaching content of practical courses in the nursing anatomy.

\begin{tabular}{|c|c|c|c|}
\hline Item & $\begin{array}{c}\text { Systematic Anatomy } \\
\text { Practice }\end{array}$ & $\begin{array}{l}\text { Living Anatomy } \\
\text { Courses }\end{array}$ & $\begin{array}{l}\text { Combining With } \\
\text { Clinical Nursing } \\
\text { Operations }\end{array}$ \\
\hline $\begin{array}{l}\text { Locomotor } \\
\text { Systems }\end{array}$ & $\begin{array}{l}\text { Main bone and } \\
\text { muscle structure } \\
\text { of the human body }\end{array}$ & $\begin{array}{l}\text { Main bone and muscle } \\
\text { landmarks of the } \\
\text { human body }\end{array}$ & \\
\hline \multirow[t]{2}{*}{$\begin{array}{l}\text { Digestive } \\
\text { system }\end{array}$} & $\begin{array}{l}\text { Digestive tract and } \\
\text { digestive glands }\end{array}$ & $\begin{array}{l}\text { Upper and lower } \\
\text { boundaries of the liver }\end{array}$ & $\begin{array}{l}\text { Anatomical path of } \\
\text { gastric intubation }\end{array}$ \\
\hline & & $\begin{array}{l}\text { Surface projection of } \\
\text { gallbladder bottom } \\
\text { Surface projection of } \\
\text { appendix root }\end{array}$ & $\begin{array}{c}\text { Anatomical path of } \\
\text { enema }\end{array}$ \\
\hline \multirow[t]{3}{*}{$\begin{array}{l}\text { Respiratory } \\
\text { system }\end{array}$} & $\begin{array}{l}\text { Respiratory tract, } \\
\text { lung, pleura }\end{array}$ & $\begin{array}{l}\text { Upper and lower } \\
\text { bounds of lung }\end{array}$ & $\begin{array}{l}\text { Anatomical level of } \\
\text { tracheotomy }\end{array}$ \\
\hline & & & $\begin{array}{l}\text { Anatomical path of } \\
\text { endotracheal intubation }\end{array}$ \\
\hline & & & $\begin{array}{l}\text { Location and peripheral } \\
\text { area of pleural puncture }\end{array}$ \\
\hline $\begin{array}{c}\text { Genitourinary } \\
\text { system }\end{array}$ & $\begin{array}{l}\text { Urinary and } \\
\text { reproductive systems }\end{array}$ & $\begin{array}{l}\text { Surface projection of } \\
\text { renal hilum }\end{array}$ & $\begin{array}{l}\text { Applied anatomy of } \\
\text { male and female } \\
\text { catheter intubation }\end{array}$ \\
\hline \multirow[t]{4}{*}{$\begin{array}{l}\text { Vascular } \\
\text { system }\end{array}$} & Structure of heart & $\begin{array}{c}\text { Surface projection } \\
\text { of heart }\end{array}$ & $\begin{array}{l}\text { Applied anatomy of } \\
\text { intracardiac injections } \\
\text { and external cardiac } \\
\text { compressions }\end{array}$ \\
\hline & Artery & $\begin{array}{l}\text { Touch of arterial pulse } \\
\text { points }\end{array}$ & \\
\hline & Vein & $\begin{array}{l}\text { Superficial veins at } \\
\text { head and neck, and } \\
\text { upper and lower } \\
\text { extremities }\end{array}$ & $\begin{array}{c}\text { Applied anatomy of } \\
\text { venous catheterization }\end{array}$ \\
\hline & & $\begin{array}{l}\text { Surface projection of } \\
\text { deep vein }\end{array}$ & \\
\hline \multirow[t]{2}{*}{$\begin{array}{l}\text { Nervous } \\
\text { system }\end{array}$} & $\begin{array}{l}\text { Central and peripheral } \\
\text { nervous system }\end{array}$ & $\begin{array}{l}\text { Surface projection of } \\
\text { peripheral nerves }\end{array}$ & \\
\hline & & Nervous reflex & \\
\hline
\end{tabular}

Based on practical mode of systematic anatomy, we highlight anatomical structures related to nursing procedures, such as bony and muscular landmarks on the body surface in the locomotor system. Anatomical landmarks related to nursing puncture, intubation and bedsores are selected for students to touch; for example, for the anatomical landmarks of the head, only the bony landmarks (the external occipital protuberance, zygomatic arch and mandibular angle) and a muscular landmark (the masseter) need to be touched. Knowledge of the bony landmarks is required for bedsores; however, knowledge of the muscular land- 
mark is required for the facial artery pulse. Practical teaching of superficial and deep veins is needed for vein catheterization, and not only enables students to observe vein trends, but also allows them to observe and compare the body location and the peripheral area to ensure that they remember clearly the anatomical structure problems encountered in the process of venipuncture. For example, in clinical nursing, infusion therapy is a means to administer medications and fluids. In the living anatomy class for jugular catheterizations, students are asked to finish the designs for the puncture site, decide the direction and angle, and provide the anatomical rationale. They then touch the anatomical landmarks, including the sternocleidomastoid, sternoclavicular joint, and clavicle, on the living body; finally, the students are asked to draw the surface projection of the jugular vein on the neck with a marker pen (Figure 3).

\subsection{Developing Online Self-Directed Learning Systems}

Modern online information service is an effective way to carry out independent learning and has many advantages. Online learning has advantages of being able to use a variety of learning methods, requiring minimal teaching time and having limited space requirements (Harden, 2006; Torres et al., 2014; Wong, Greenhalgh, \& Pawson, 2010). By making full use of modern network technology, we have built an independent learning platform and evaluation system with independent intellectual property rights for students. Online courses, including human anatomy and human structure, are available on the campus network. Additionally, corresponding curriculum forums for human anatomy and human structure have also been created; the learning software-"learning and exam system for network independent study of human anatomy" is the first of its kind in China. This system includes over 3000 anatomical specimen structure pictures for identification, and over 4000 single and multiple-choice questions. Each

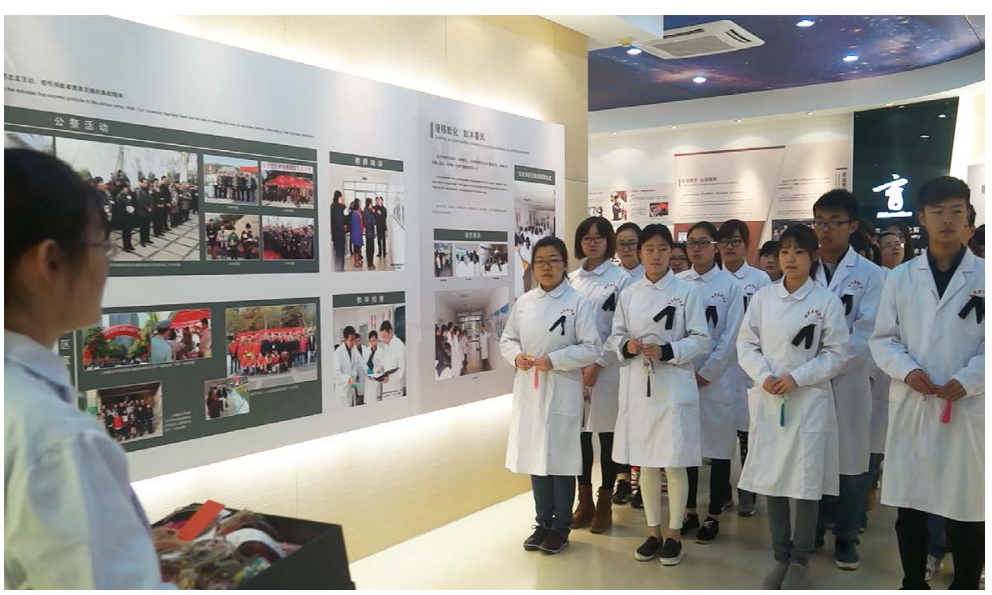

Figure 3. Gratitude education. Students are invited to the "Medical Ethics Education Center" in the first practical class of nursing anatomy, to understand the body donation procedure and the deeds of the donors. The students wore black ribbons on their chests, hand-picked the commemorative donor's wish cards, and decorated the pavilion with their wish cards. 
question is graded according to its difficulty level, which is suitable for self-directed learning and self-testing of students from different specialties. Students may assess their progress at any time. Each year, the school recruits about 300 undergraduate nursing students. According to the statistics of the platform, nursing students log on to the system about 25,000 times a year, with an average of more than 80 times per year. We have demonstrated that this system improves students' overall grasp of the anatomy curriculum, and this system is successful in providing a thorough education in anatomy rather than just enabling the students to pass their anatomy exams. The construction of the self-directed learning platform enables the practical teaching of anatomy out of the classroom, extends the teaching time and helps students broaden their horizons and think actively, promoting the training and development of their learning abilities.

\subsection{Strengthening Humanistic Qualities in Medicine}

Nursing is a profession that directly sustains human life and health, and is an example of the humanistic spirit of medicine (Loke, Fung, \& Liu, 2013). Modern medical education requires that students not only have a superb nursing care technique, but also need to have excellent humanistic qualities and professional ethics (Borhani, Abbaszadeh, \& Mohsenpour, 2013; Parsons, Barker, \& Armstrong, 2001). We pay equal attention to the teaching of anatomy and humanistic spirit, especially in the practical teaching program; we emphasize the integration of the knowledge of anatomy and humanistic spirit within nursing. According to the characteristics of human anatomy, we strengthen medical ethics and gratitude education, train the quality of medical humanities comprising of reverence for life, selfless dedication in undergraduate nurses.

A Medical Ethics Education Center (Zhang, Wang, Xiao, Han, \& Ding, 2008; Zhang et al., 2014) has been set up at Nanjing Medical University, and is an important focus for medical humanism education and outreach, but also provides a course that is a compulsory part of the human anatomy curriculum. It helps students understand the selfless dedication of the body donors and cultivates a spirit of respecting life.

The first nursing anatomy class at Nanjing Medical University focuses on the human issues and expresses gratitude to body donors for their contribution. The anatomical class in each semester begins with a thanksgiving ceremony for donors and a moment of silence to show the proper degree of respect for donors, and as a comfort for the relatives of the donors (Figure 4). Special care has been taken to ensure the responsible and respectful treatment of donors' bodies in the daily activities of the dissection lab.

\section{Conclusion}

It has become widely accepted that nursing education, especially basic medical education, requires reforming. In the report "Proposal on analysis of China 


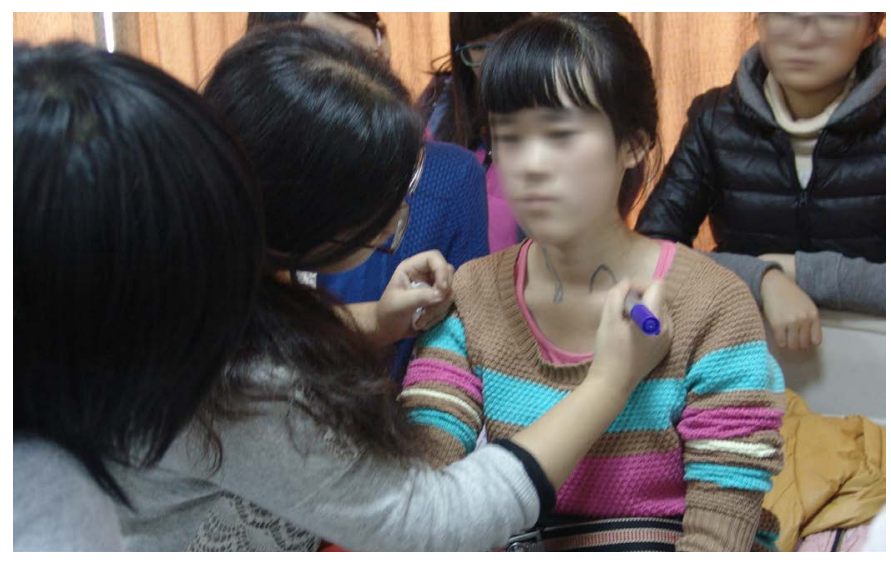

Figure 4. An experimental living body-touch class requires students to mark on the body with marker pens after touching important anatomical landmarks.

nursing human resources and strengthening development and training of urgently needed nursing personnel" the Department of Medical Science, Technology, and Education, $\mathrm{MOH}$, China, points out that "in accelerating the teaching reform of nursing education, the proportion of basic medical knowledge should be reduced in the professional basic course while the content closely relevant with nursing work be increased, so as to highlight the content and features of nursing" (Department of Medical Science, 2004). With the development of nursing education, the time spent in class for the basic medical course (including human anatomy class) of the nursing specialty will gradually be cut down; however, practice has proved that the self-learning system and learning platform based on Internet technology expand learning space, enhance students' interest in learning and improve learning efficiency. At the same time, the professional knowledge and humanities courses will be increased, representing the development trends of practical training in the nursing profession.

\section{Grant Sponsor}

This work was supported by grants from Philosophy and Social Science Research Project of Jiangsu Provincial Universities, P. R. China (Grant number: 2015SJB162); The 12th Five-Year Project for Education Science in Jiangsu Province (Grant number: B-b/2015/01/051); Undergraduate Innovation and Enterprise Training Project of Jiangsu Provincial Universities, China (Grant number: 201810312034Y); Educational Reform Project of Nanjing Medical University, Nanjing, China (Grant number: YB2017114).

\section{Conflicts of Interest}

The authors declare no conflicts of interest regarding the publication of this paper.

\section{References}

Aversi-Ferreira, T., Lopes, D., Reis, S., Abreu, T., Aversi-Ferreira, R., Vera, I., \& Lucchese, 
R. (2009). Practice of Dissection as Teaching Methodology in Anatomy for Nursing Education. Brazilian Journal of Morphological Sciences, 26, 151-157.

Becker, S., Viljoen, M., Botma, Y., \& Bester, I. (2003). Integration of Study Material in the Problem-Based Learning Method. Curationis, 26, 57-61. https://doi.org/10.4102/curationis.v26i1.1295

Biasutto, S. N., Caussa, L. I., \& del Río, L. E. C. (2006). Teaching Anatomy: Cadavers vs. Computers? Annals of Anatomy-Anatomischer Anzeiger, 188, 187-190. https://doi.org/10.1016/j.aanat.2005.07.007

Borhani, F., Abbaszadeh, A., \& Mohsenpour, M. (2013). Nursing Students' Understanding of Factors Influencing Ethical Sensitivity: A Qualitative Study. Iranian Journal of Nursing Midwifery Research, 18, 310-315.

Department of Medical Science (2004). Proposal on Analysis of China Nursing Human Resources and Strengthening Development and Training of Urgently Needed Nursing Personnel. Chinese Vocational and Technical Education, 18, 15-18.

Harden, R. (2006). Trends and the Future of Postgraduate Medical Education. Emergency Medicine Journal, 23, 798-802. https://doi.org/10.1136/emj.2005.033738

Loke, A. Y., Fung, W., \& Liu, X. (2013). Mainland China Nurses' Willingness to Report to Work in a Disaster. American Journal of Disaster Medicine, 8, 273-282. https://doi.org/10.5055/ajdm.2013.0134

Parsons, S., Barker, P. J., \& Armstrong, A. E. (2001). The Teaching of Health Care Ethics To students of Nursing in the UK: A Pilot Study. Nursing Ethics, 8, 45-56. https://doi.org/10.1177/096973300100800106

Saltarelli, A. J., Roseth, C. J., \& Saltarelli, W. A. (2014). Human Cadavers vs. Multimedia Simulation: A Study of Student Learning in Anatomy. Anatomical Sciences Education, 7, 331-339. https://doi.org/10.1002/ase.1429

Torres, K., Torres, A., Lisiecka, J., Błoński, M., Bącik-Donica, M., Staśkiewicz, G., \& Maciejewski, R. (2014). Simulation Techniques in the Anatomy Curriculum: Review of Literature. Folia Morphologica, 73, 1-6. https://doi.org/10.5603/FM.2014.0001

Wong, G., Greenhalgh, T., \& Pawson, R. (2010). Internet-Based Medical Education: A Realist Review of What Works, for Whom and in What Circumstances. BMC Medical Education, 10, 12. https://doi.org/10.1186/1472-6920-10-12

Xiong, S., Yang, X., Ji, R., \& Zhang, C. (2008). Exploration on the Teaching of Nursing Applied Anatomy. Chinese Journal of Anatomy, 4, 453,488.

Zhang, L., Wang, Y., Xiao, M., Han, Q., \& Ding, J. (2008). An Ethical Solution to the Challenges in Teaching Anatomy with Dissection in the Chinese Culture. Anatomical Sciences Education, 1, 56-59. https://doi.org/10.1002/ase.15

Zhang, L., Xiao, M., Gu, M., Zhang, Y., Jin, J., \& Ding, J. (2014). An Overview of the Roles and Responsibilities of Chinese Medical Colleges in Body Donation Programs. Anatomical Sciences Education, 7, 312-320. https://doi.org/10.1002/ase.1422 